\title{
$A \beta$ impairs nicotinic regulation of inhibitory synaptic transmission and interneuron excitability in prefrontal cortex
}

\author{
Guo-Jun Chen ${ }^{1 *}$, Zhe Xiong ${ }^{2}$ and Zhen Yan ${ }^{2 *}$
}

\begin{abstract}
Background: Accumulation of $\beta$-amyloid (A $\beta$ ) and cholinergic deficiency are two prominent features of Alzheimer's disease (AD). To understand how $A \beta$-induced dysfunction of the nicotinic system may contribute to cognitive impairment in $A D$, we examined the effect of $A \beta$ on nicotinic regulation of synaptic transmission and neuronal excitability in prefrontal cortex (PFC), a brain region critical for cognitive processes.

Results: We found that activation of nicotinic acetylcholine receptors (nAChRs) with nicotine increased the inhibitory postsynaptic currents recorded in PFC pyramidal neurons, which was associated with the nicotine-induced increase in the excitability of PFC layer I GABAergic interneurons. Both effects of nicotine were disrupted by $A \beta$. However, $A \beta$ did not impair nicotinic regulation of excitatory neurotransmission in PFC interneurons. The nicotinic effect on synaptic inhibition was also lost in transgenic mice with five familial Alzheimer's disease mutations. Inhibiting PKC attenuated nicotinic regulation of inhibitory, but not excitatory, neurotransmission.
\end{abstract}

Conclusions: Our study suggests that $A \beta$ selectively impairs nicotinic regulation of inhibitory inputs to PFC pyramidal neurons, which might be due to its interference with PKC activation. Thus, in the PFC circuits of AD, the balance between inhibition and excitation under the control of nAChRs may be disturbed by A .

Keywords: Alzheimer's disease, $\beta$-amyloid, Nicotinic acetylcholine receptor, Prefrontal cortex, Interneuron, Pyramidal neuron, Inhibitory postsynaptic current, Firing, Protein kinase $C$

\section{Background}

$A \beta$ plays a critical role in the pathogenesis of Alzheimer's disease $(\mathrm{AD})$ [1-4]. Earlier studies show that $\mathrm{A} \beta$ can cause cell death in cultured neurons [5] by inducing oxidative stress and disrupting intracellular calcium homeostasis [6]. Recent evidence suggests that the cognitive deficit and memory loss in early stages of $\mathrm{AD}$ are due to synaptic failure [7] and functional changes in the activity of neuronal network [8]. However, the role of $A \beta$ in synaptic dysfunction in $\mathrm{AD}$ is far from clear.

In addition to $A \beta$ accumulation, another hallmark of $\mathrm{AD}$ is a selective loss of cholinergic neurons in basal forebrain [9], and the loss of nicotinic acetylcholine

\footnotetext{
* Correspondence: woodchen2015@163.com; zhenyan@buffalo.edu 'Department of Neurology, The First Affiliated Hospital of Chongqing Medical University, Chongqing 400016, China ${ }^{2}$ Department of Physiology and Biophysics, State University of New York at Buffalo, New York 14214, USA
}

receptors (nAChRs) in the hippocampus and cortex $[10,11]$. Neuronal $\mathrm{nAChR}$ is a pentameric structure formed from $\alpha$ - and $\beta$ - subunits $(\alpha 2-\alpha 10, \beta 2-\beta 4)$. nAChRs are distributed in both presynaptic and postsynaptic sites [12,13], regulating transmitter release, synaptic response and neuronal excitability [14]. Animal studies have found that $\mathrm{nAChR}$ activation improves working memory $[15,16]$, while nAChR antagonist, mecamylamine, impairs attention accuracy or reaction time $[17,18]$. Clinical drugs targeting $\mathrm{nAChRs}$ improve symptoms in AD patients [19].

It has been suggested that $\mathrm{nAChRs}$ are involved in regulating the integrated circuit activity between interneurons and projection neurons [20,21]. We hypothesize that $A \beta$ may interrupt nicotinic regulation of inhibitory/ excitatory balance at cortical circuits, thus contributing to the loss of cognition and memory in AD. To test this, we examined the effect of nicotine on inhibitory inputs 
to cortical pyramidal neurons and the excitatory inputs to cortical interneurons, as well as the potential impact of $A \beta$ on the regulatory effects of nAChRs.

\section{Results}

Nicotine increases inhibitory neurotransmission in PFC layer $\mathrm{V}$ pyramidal neurons through non- $\alpha \mathrm{7} \mathrm{nACh}$ receptors

We first assessed the effect of nAChR activation on inhibitory neurotransmission in layer $\mathrm{V}$ pyramidal neurons in the prefrontal cortex (PFC). Nicotine $(5 \mu \mathrm{M},[22,23])$ was applied to the bath solution for $10 \mathrm{~min}$. As shown in Figure 1A-D, nicotine significantly increased sIPSC amplitudes, as indicated by a rightward shift of their distribution. Moreover, nicotine significantly increased sIPSC frequencies, as indicated by a leftward shift of the distribution of inter-event intervals. The effect of nitonine on sIPSC was reversible. Note that sIPSC was completely blocked by bicuculline $(10 \mu \mathrm{M})$, indicating its mediation by $\mathrm{GABA}_{\mathrm{A}}$ receptors (Figure $1 \mathrm{~A}$ ). In the sample of cells we tested, nicotine increased sIPSC amplitude by $41.1 \pm 7.0 \%$ and frequency by $32.1 \pm 9.3 \%(n=9$, Figure 1D).
To identify the possible receptor subtypes that mediate the nicotinic effect, we applied nAChR antagonists to PFC slices. As shown in Figure 1D, mecamylamine (MEC, $10 \mu \mathrm{M})$, a non- $\alpha 7 \mathrm{nAChR}$ antagonist, largely blocked the effect of nicotine on SIPSC amplitude (0.4 \pm $1.6 \%, \mathrm{n}=5)$ and frequency $(12.6 \pm 4.1 \%, \mathrm{n}=5)$. In contrast, in the presence of methyllycaconitine (MLA, $1 \mu \mathrm{M}$ ), an $\alpha 7$ $\mathrm{nAChR}$ antagonist, the effect of nicotinic on sIPSC was not significantly changed (amplitude: $41.1 \pm 6.9 \%$, frequency: $41.3 \pm 3.8 \%, n=6$ ). It suggests that the nicotinic effect on sIPSC in layer V PFC pyramidal neurons is mediated by non- $\alpha 7 \mathrm{nAChRs}$.

\section{Nicotine boosts the excitability of PFC layer I GABAergic interneurons}

To assess whether nicotinic enhancement of sIPSC is due to nAChR-induced increase in the excitability of PFC GABAergic interneurons, we examined the effect of nicotine on action potential firing of interneurons in PFC. Since layer I of neocortex contains exclusively GABAergic interneurons with extensive axonal plexus innervating neurons in deep layers [24-26], we focused our studies on PFC layer I GABAergic interneurons.
A

$A$

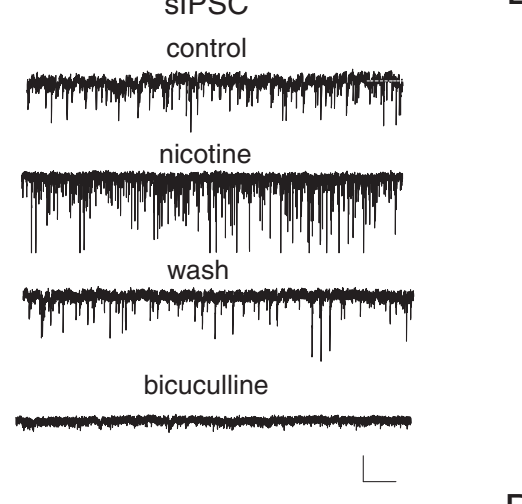

C

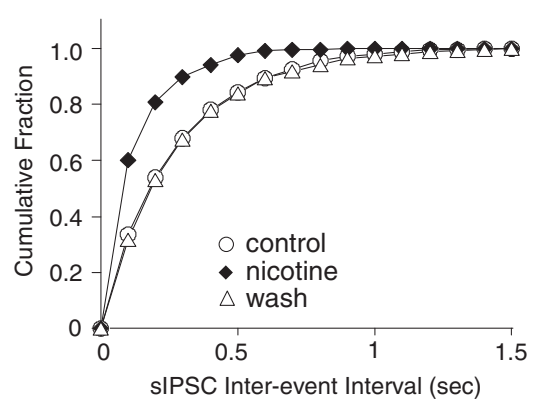

B
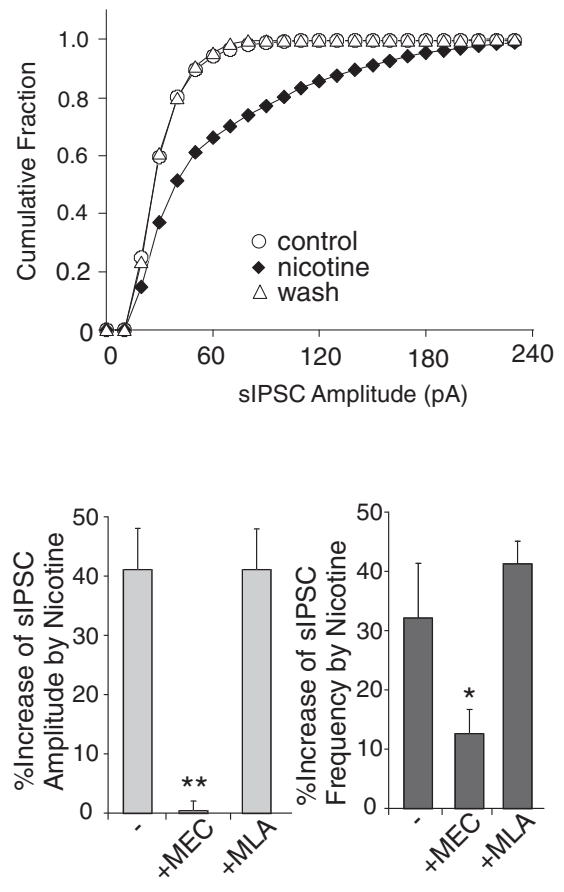

Figure 1 Nicotine enhanced sIPSC in PFC layer V pyramidal neurons. A-D, Representative sIPSC traces (A) and cumulative plots of the distribution of sIPSC amplitude (B) and frequency $(\mathbf{C})$ in the absence (control, wash) or presence of nicotine $(5 \mu \mathrm{M})$ recorded in a PFC pyramidal neuron. The blockade of sIPSC by bicuculline $(10 \mu \mathrm{M})$ was also shown in A. Scale bars $(\mathbf{A}): 50$ pA, $5 \mathrm{~s}$. D, Bar plot summary of the percentage increase of sIPSC amplitude and frequency by nicotine in the absence or presence of MEC (mecamylamine, $10 \mu \mathrm{M}$, a non-a7 nAChR antagonist) or MLA (methyllycaconitine, $1 \mu \mathrm{M}$, an a7 nAChR antagonist). *: $p<0.05,{ }^{* *}: \mathrm{p}<0.005$, ANOVA. 
As shown in Figure 2A, nicotine caused a significant increase in the spike number in the representative layer I interneuron. We noticed that nicotine caused a significant change in the resting potential in a portion of layer I interneurons $(6 / 15, \Delta \mathrm{Rm}>5 \%$, from $-66.4 \pm 3.5 \mathrm{mV}$ to $-60.4 \pm 3.4 \mathrm{mV})$, but not in others $(9 / 15, \Delta \mathrm{Rm}<5 \%$, from $-68.7 \pm 2.9 \mathrm{mV}$ to $-67.3 \pm 3.0 \mathrm{mV}$ ). The $\mathrm{Rm}$ change is similar to the nicotine-induced depolarization in some hippocampal neurons [27]. So we divided these cells into two groups before evaluating the effect of nicotine on the firing rate. As shown in Figure 2B, nicotine significantly increased the firing rate in both groups $(\Delta \mathrm{Rm}<5 \%$ : $30.8 \pm 6.7 \%, \quad n=9 ; \quad \Delta R m>5 \%: 56.5 \pm 16.4 \%, \quad n=6)$. In the presence of $\mathrm{nAChR}$ antagonist MEC or MLA, nicotine failed to change the resting potential in all neurons we tested (MEC-treated cells: $-60.9 \pm 2.2 \mathrm{mV}$ to $-60.4 \pm 2.3 \mathrm{mV}, \mathrm{n}=7$; MLA-treated cells: $-70.7 \pm 1.8$ to $-69.7 \pm 1.8 \mathrm{mV}, \mathrm{n}=8$ ). However, the nicotinic effect on firing rate was significantly attenuated by MEC (Figure $2 \mathrm{~B}, 8.6 \pm 3.3 \%, \mathrm{n}=7$ ) or MLA (Figure $2 \mathrm{~B}, 11.8 \pm$ $4.4 \%, \mathrm{n}=8$ ), suggesting that both non- $\alpha 7$ and $\alpha 7 \mathrm{nAChRs}$ are involved in nicotinic enhancement of interneuron excitability.
We also assessed whether nicotine affects the excitability of deep layer neurons. We found that nicotine did not cause a significant increase in the firing rate or resting potential of layer $V$ fast-spiking interneurons $(n=5)$. Nicotine also failed to show any significant effect on the firing rate of layer $V$ pyramidal neurons $(n=5)$.

\section{$A \beta$ attenuates the nicotinic effect on inhibitory} transmission in layer $\mathrm{V}$ cortical pyramidal neurons

Given the involvement of cholinergic hypofunction in $\mathrm{AD}$, we next examined whether $\mathrm{A} \beta$ could alter the nicotinic regulation of inhibitory synaptic transmission in PFC pyramidal neurons. $A \beta$ oligomers were generated as we described and characterized before [28]. PFC slices were incubated with $A \beta$ oligomers $(1 \mu \mathrm{M}$, [28-30]) for at least 3 hours before recording. No significant difference in basal sIPSC was observed after $A \beta$ treatment (nontreated: $35.2 \pm 2.2 \mathrm{pA}, 5.5 \pm 1.1 \mathrm{~Hz}, \mathrm{n}=5 ; \mathrm{A} \beta$-treated: $36.8 \pm 2.4 \mathrm{pA}, 6.1 \pm 1.0 \mathrm{~Hz}, \mathrm{n}=5$ ). However, nicotine failed to increase the amplitude or frequency of sIPSC in A $\beta$-treated neurons. A representative example is shown in Figure 3A-C. As summarized in Figure 3D, in layer $\mathrm{V}$ pyramidal neurons pretreated with $A \beta$, the nicotine-

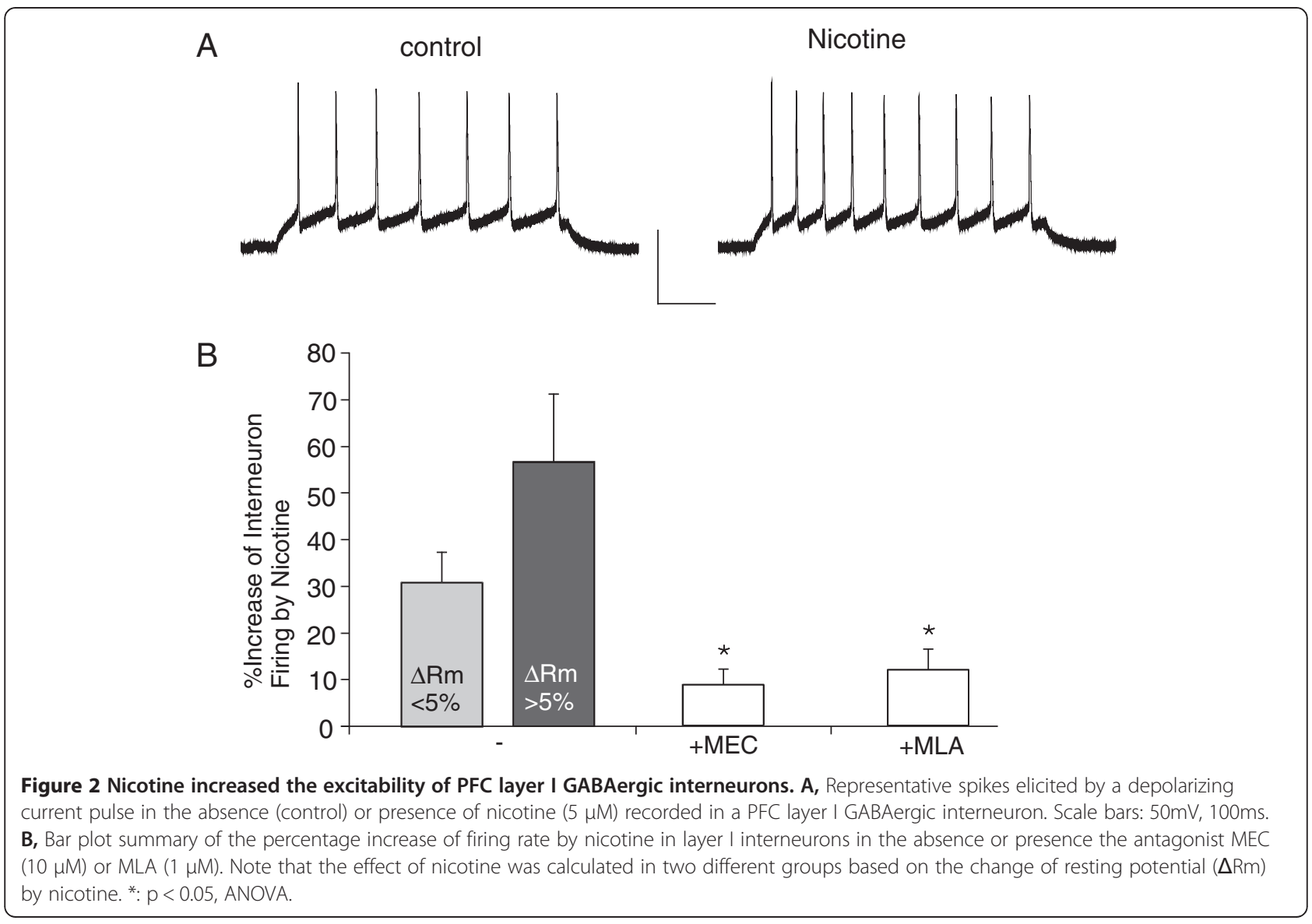



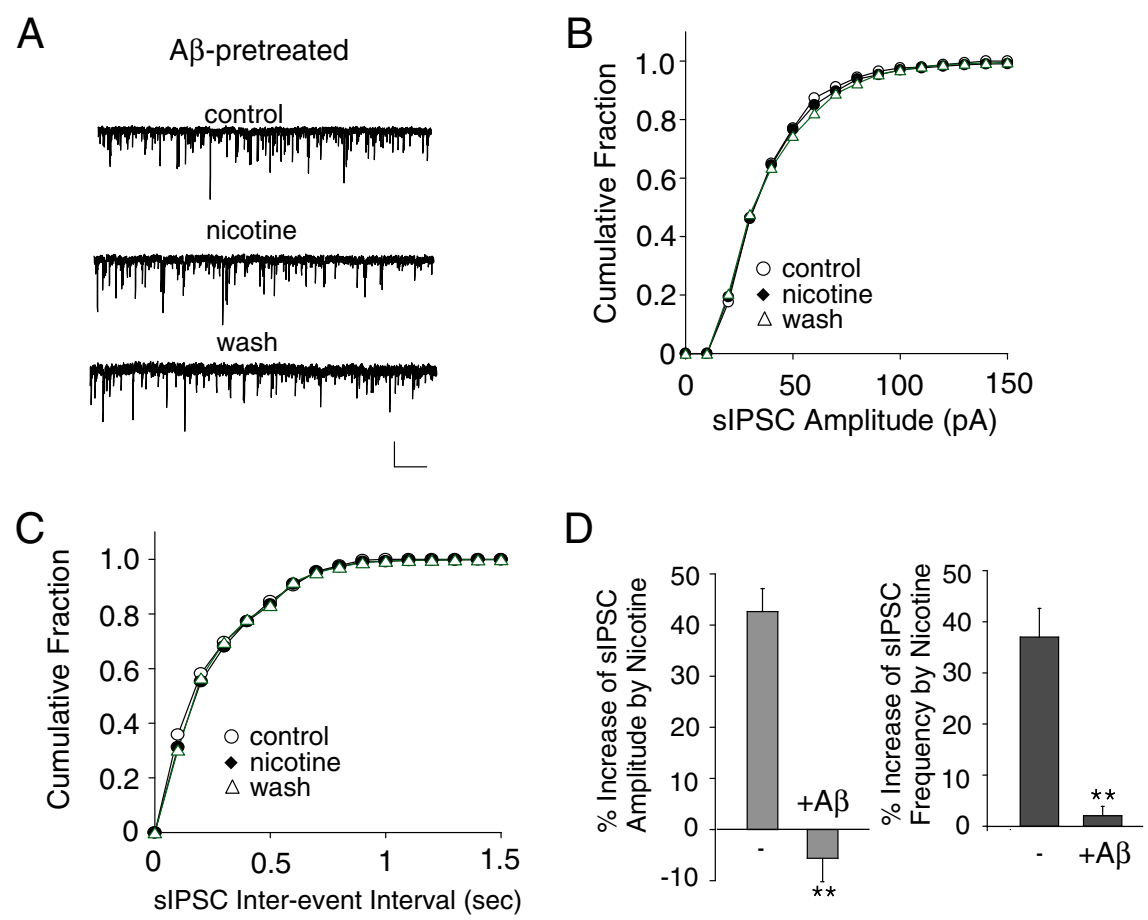

Figure $3 \mathbf{A} \boldsymbol{\beta}$ diminished the nicotinic effect on sIPSC in PFC layer $\mathbf{V}$ pyramidal neurons. A-C, Representative sIPSC traces $(\mathbf{A})$ and cumulative plots of the distribution of sIPSC amplitude $(\mathbf{B})$ and frequency $(\mathbf{C})$ in the absence (control) or presence of nicotine $(5 \mu \mathrm{M})$ recorded in a PFC pyramidal neuron pre-incubated with $A \beta$ oligomer (1 $\mu \mathrm{M}, 3$ hours). Scale bars (A): 100pA, 15s. D, Bar plot summary of the percentage change of sIPSC amplitude and frequency by nicotine in PFC pyramidal neurons with or without A $\beta$ pretreatment. ${ }^{*}: p<0.05,{ }^{* *}: p<0.01, t$-test.

induced change in sIPSC amplitude $(-5.6 \pm 4.47 \%, \mathrm{n}=5)$ and frequency $(2.03 \pm 1.87 \%, \mathrm{n}=5)$ was significantly smaller than that in non-treated control cells (amplitude: $41.2 \pm 5.1 \%$, frequency: $36.4 \pm 7.8 \%, \mathrm{n}=4$ ).

To confirm that the observed effect of $A \beta$ also occurs in vivo, we examined the transgenic mice with five familial Alzheimer's disease mutations (5xFAD), which rapidly recapitulate major features of $\mathrm{AD}$ amyloid pathology. These mice start to accumulate intraneuronal $A \beta 42$ at $\sim 1.5$ months of age within neuron soma and neurites and amyloid deposition reaches a very large burden in deep cortical layers [31]. As shown in Figure 4, nicotine $(5 \mu \mathrm{M})$ had almost no effect on sIPSC in 1.2-month-old 5xFAD mice (amplitude: $6.7 \pm 1.8 \%$, frequency: $7.1 \pm$ $1.9 \%, \mathrm{n}=4$ ), which was significantly different from the enhancing effect of nicotine on sIPSC in age-matched WT mice (amplitude: $24.2 \pm 4.8 \%$, frequency: $31.6 \pm$ $5.2 \%, n=6$ ). These results suggest that $A \beta$ impairs nicotinic regulation of inhibitory synaptic transmission in PFC.

$A \beta$ weakens the nicotinic effect on the excitability of PFC layer I GABAergic interneurons

Since the nicotinic effect on SIPSC is due to its regulation of the excitability of GABAergic interneurons, we next examined whether $A \beta$ also interferes with the nicotinic effect on action potential firing of layer I interneurons. PFC slices were pretreated with $A \beta$ oligomers $(1 \mu \mathrm{M})$ for at least 3 hours before recording. Nicotine significantly increased the firing rate in non-treated control neurons, but not in $\mathrm{A} \beta$-treated neurons. Representative examples are shown in Figure $5 \mathrm{~A}$ and $5 \mathrm{~B}$. As summarized in Figure $5 \mathrm{C}$, in all the neurons pooled together $(\Delta R m>5 \%$ and $\Delta R m<5 \%)$, nicotine caused a significantly smaller effect on the firing rate of $A \beta$-treated interneurons $(14.3 \pm 8.5 \%, \mathrm{n}=9)$ than control cells $(41.1 \pm$ $7.5 \%, \mathrm{n}=15)$. In the subgroups with $\Delta \mathrm{Rm}<5 \%$, the effect of nicotine on the firing rate in $A \beta$-treated cells $(5.2 \pm$ $2.4 \%, \mathrm{n}=7$ ) was also significantly smaller than that in control cells $(33.0 \pm 6.2 \%, n=9)$. It suggests that $A \beta$ impairs nicotinic regulation of GABAergic interneuron excitability in PFC.

\section{$A \beta$ does not interfere with nicotinic regulation of excitatory neurotransmission}

Given the $A \beta$-induced impairment of nicotinic regulation of inhibitory transmission and interneuron excitability, we would like to know whether $A \beta$ also impairs nicotinic regulation of excitatory transmission. To do so, we examined the effect of nicotine on spontaneous EPSC (sEPSC) in layer I interneurons treated with or without $A \beta$. As shown in Figure $6 \mathrm{~A}-\mathrm{C}$, nicotine caused a significant 


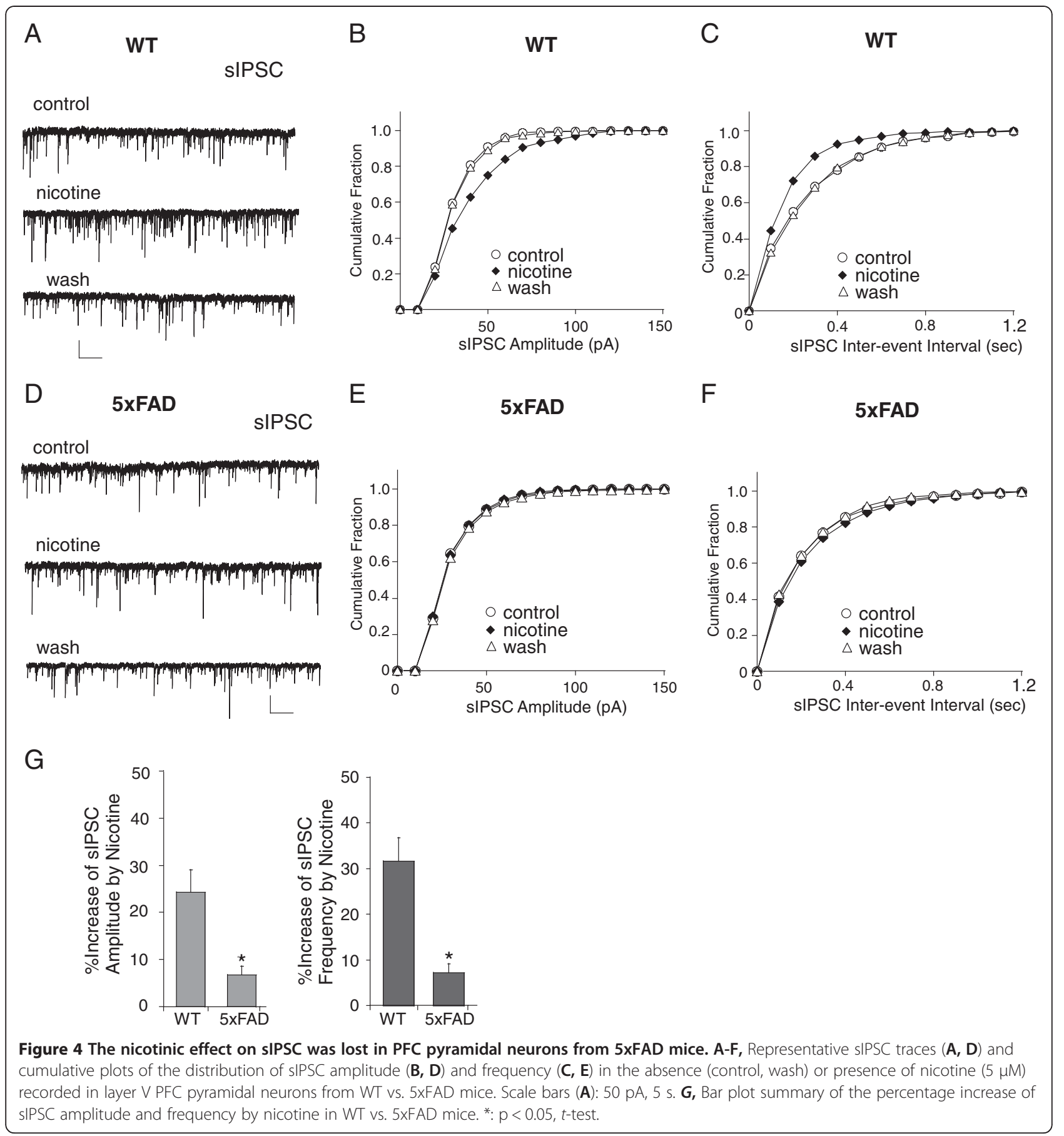

increase in the sEPSC frequency, but not sEPSC amplitude, in non-treated control cells. Similar effects were observed in A $\beta$-treated cells (Figure 6D-F). Note that sEPSC was completely blocked by DNQX $(20 \mu \mathrm{M})$ plus APV $(40 \mu \mathrm{M})$, indicating its mediation by glutamate receptors (Figure 6A). As summarized in Figure 6G, the nicotine-induced enhancement of sEPSC frequency was not significantly altered by $\mathrm{A} \beta$ treatment (non-treated: $103.3 \pm 27.5 \%, \mathrm{n}=10$; $\mathrm{A} \beta$-treated: $83.0 \pm 25.9 \%, \mathrm{n}=9$ ).
Why does $A \beta$ differentially affect nicotinic regulation of excitatory vs. inhibitory neurotransmission? One possibility is that distinct $\mathrm{nAChR}$ subtypes mediate the nicotinic effect on sEPSC or sIPSC. To test this, we applied specific nAChR antagonists. As shown in Figure $6 \mathrm{H}$, in cells treated with the non- $\alpha 7 \mathrm{nAChR}$ antagonist MEC $(10 \mu \mathrm{M})$, nicotine failed to increase sEPSC frequency $(2.6 \pm 1.6 \%, n=4)$. In contrast, the nicotinic enhancement of sEPSC frequency $(97.9 \pm 9.9 \%, n=4)$ 

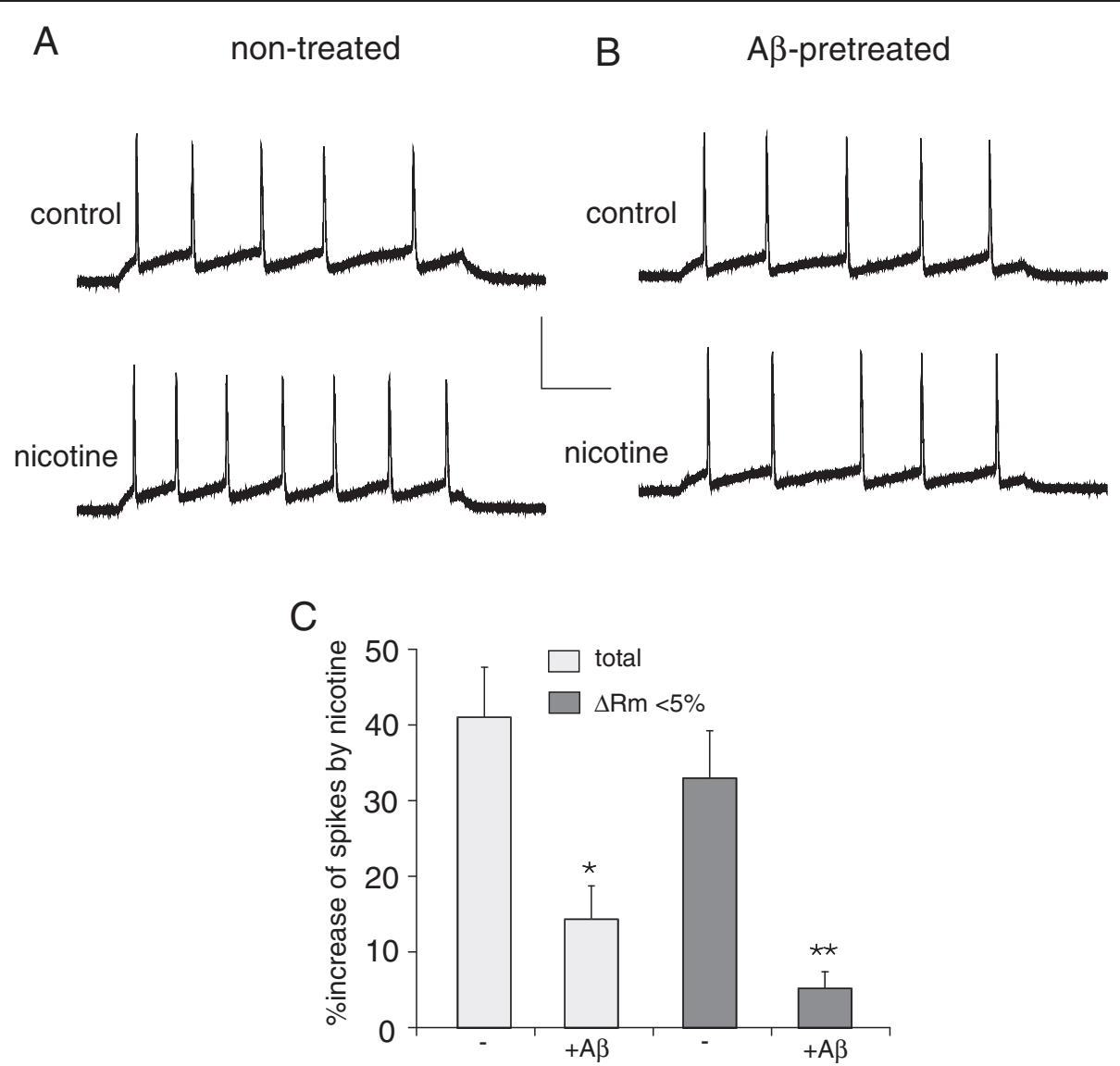

Figure $5 \mathrm{~A} \boldsymbol{\beta}$ attenuated the nicotinic effect on layer I interneuron excitability. A, B, Representative spikes elicited by a depolarizing current pulse in the absence (control) or presence of nicotine $(5 \mu \mathrm{M})$ recorded in PFC layer I GABAergic interneurons without (A) or with $A \beta$ pretreatment (B). Scale bars: $50 \mathrm{mV}, 100 \mathrm{~ms}$. C, Bar plot summary of the percentage increase of firing rate by nicotine in non-treated $(-)$ and $A \beta-$ pretreated layer I interneurons. Note that the effect of nicotine was calculated in two different groups based on the change of resting potential $(\Delta \mathrm{Rm})$ by nicotine. ${ }^{*}: \mathrm{p}<0.05,{ }^{* *}: p<0.01$, ANOVA.

was intact in cells treated with the $\alpha 7 \mathrm{nAChR}$ antagonist MLA $(1 \mu \mathrm{M})$. It suggests that non- $\alpha 7$ nAChRs play a major role in mediating the nicotinic effect on excitatory neurotransmission, which is similar to their major role in mediating the nicotinic effect on inhibitory neurotransmission. Thus, the differential effects of $\mathrm{A} \beta$ on nicotinic regulation of sIPSC and sEPSC can not be explained by the nAChRs involved.

\section{PKC is differentially involved in nicotinic regulation of inhibitory vs. excitatory neurotransmission}

Having excluded the possibility that nAChR subtypes may contribute to the selective effect of $A \beta$ on nicotinic regulation of inhibitory transmission, we hypothesize that $A \beta$ might interfere with some downstream signaling molecule that is differentially involved in the nicotinic regulation of sIPSC or sEPSC. Our previous studies have found that PKC activation is often impaired by $A \beta$ treatment $[30,32,33]$, so we examined the involvement of PKC in nicotinic regulation of sIPSC and sEPSC. PFC slices were pre-incubated with a PKC inhibitor for at least 1 hour, and sIPSC was recorded in layer V pyramidal neurons and sEPSC was recorded in layer I GABAergic interneurons.

As shown in Figure 7A-C, in PFC pyramidal neurons treated with the potent and selective PKC inhibitor GF109203X $(1 \mu \mathrm{M})$, nicotine failed to cause a significant increase in the sIPSC amplitude $(-3.2 \pm 1.7 \%, \mathrm{n}=7$, Figure 7G), and had a significantly attenuated effect on sIPSC frequency $(18.9 \pm 8.7 \%, \mathrm{n}=7)$, which was contrary to the effects of nicotine on sIPSC in control cells (sIPSC amplitude: $39.4 \pm 1.7 \%$; sIPSC frequency: $34.2 \pm$ $7.4 \%, \mathrm{n}=5$ ). However, nicotine still caused a significant increase in the sEPSC frequency in GF109203X-treated interneurons (Figure 7D-F, $97.4 \pm 12.6 \%, n=8$, Figure 7H), similar to its effect on sEPSC frequency in control cells $(106.1 \pm 26.3 \%, \mathrm{n}=5)$.

To further confirm the involvement of PKC in nicotinic regulation of synaptic inhibition, we also treated neurons with a different type of highly specific PKC 


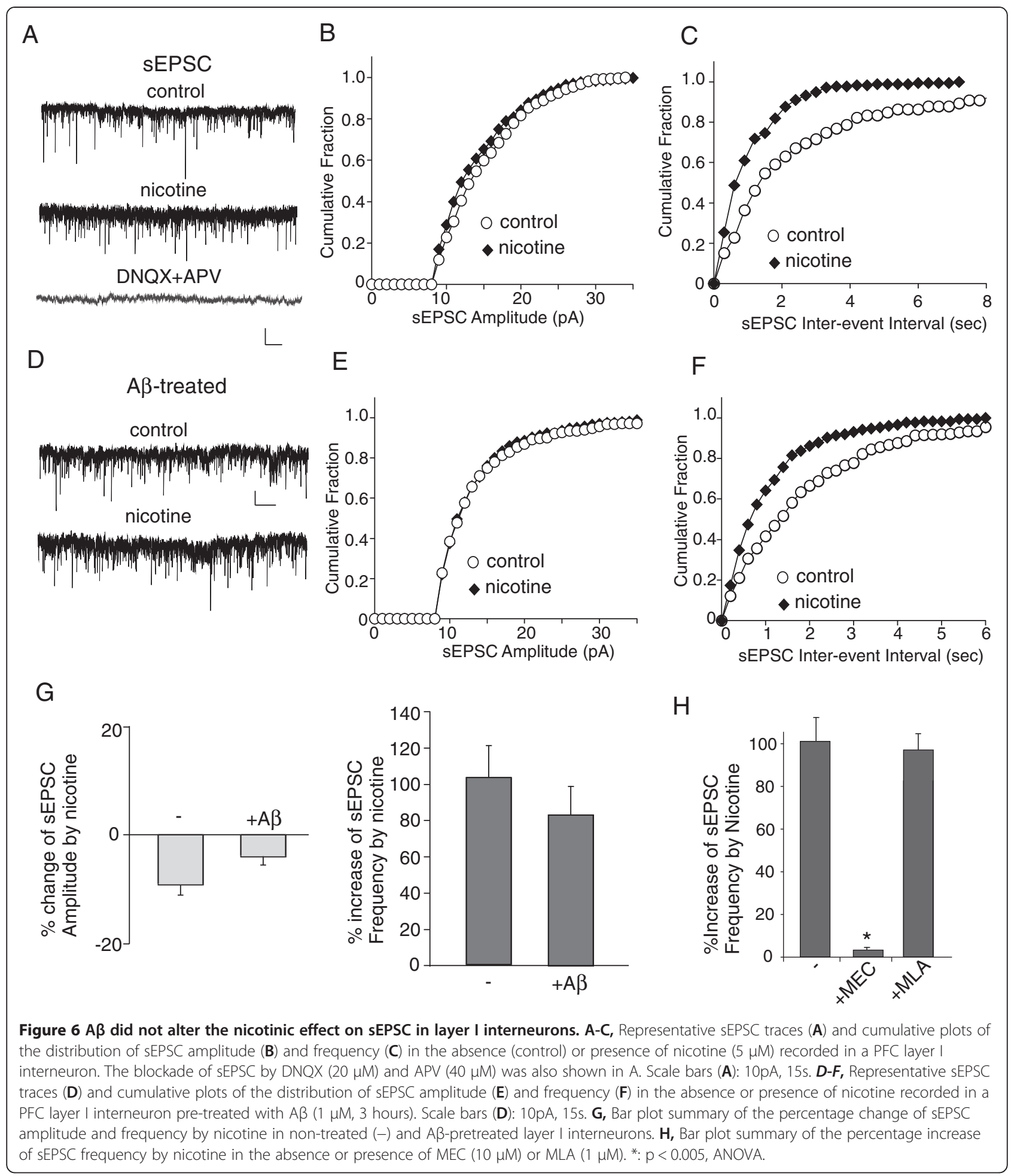

inhibitor, $\mathrm{PKC}_{20-28}$, which is a peptide containing the pseudosubstrate sequence from PKC $\alpha$ and PKC $\beta$. $\mathrm{N}$-Terminus is myristoylated to allow membrane permeability. As shown in Figure 8, in myr- $\mathrm{PKC}_{20-28}$ $(10 \mu \mathrm{M}, 1 \mathrm{hr})$-treated neurons, nicotine $(5 \mu \mathrm{M})$ had significantly diminished enhancing effect on mIPSC amplitude (control: $44.1 \pm 13.6 \%, \mathrm{n}=4, \mathrm{PKC}_{20-28}: 16.5 \pm$ $3.8 \%, \mathrm{n}=5$ ) and frequency (control: $36.0 \pm 7.1 \%, \mathrm{n}=4$, $\mathrm{PKC}_{20-28}: 9.9 \pm 2.2 \%, \mathrm{n}=5$ ). These results suggest that PKC activation is required for nicotinic regulation of inhibitory, but not excitatory, synaptic transmission in PFC. 


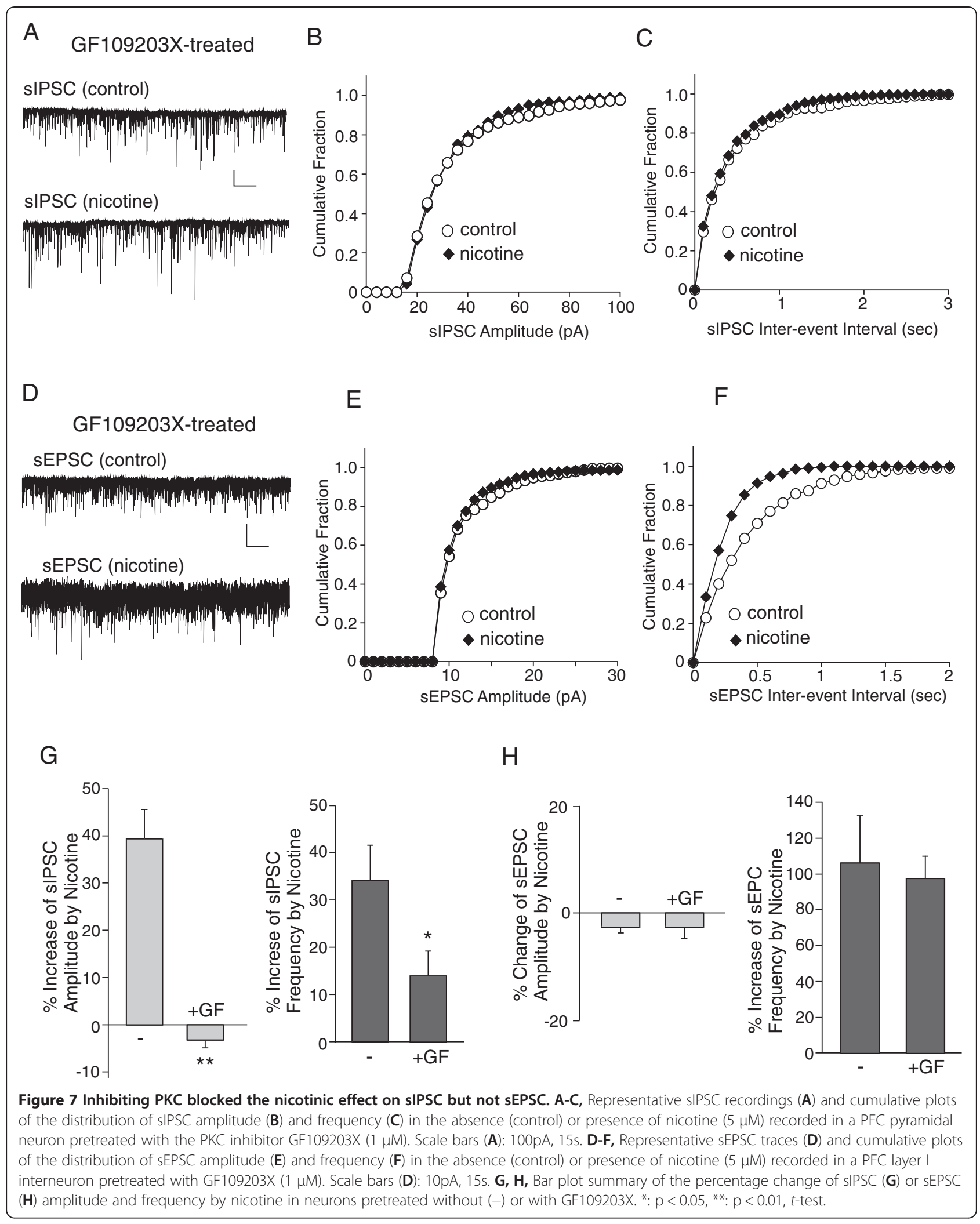



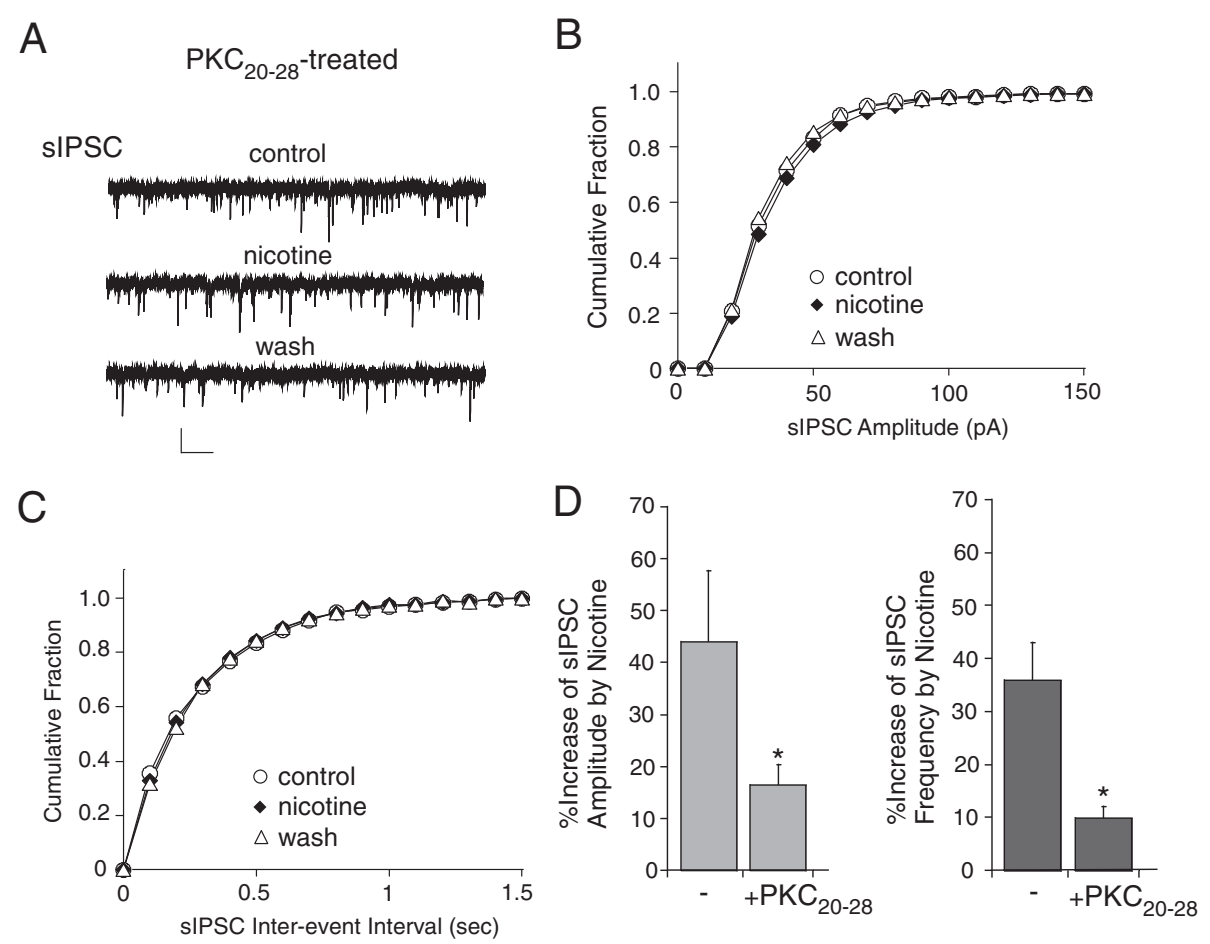

Figure 8 Highly specific PKC inhibitor blocked the nicotinic effect on sIPSC. A-C, Representative sIPSC traces (A) and cumulative plots of the distribution of sIPSC amplitude (B) and frequency $(\mathbf{C})$ in the absence (control) or presence of nicotine $(5 \mu \mathrm{M})$ recorded in a PFC pyramidal neuron pretreated with myristolated PKC inhibitor 20-28 (10 $\mu$ M). Scale bars (A): 50 pA, 5 s. D, Bar plot summary of the percentage increase of sIPSC amplitude and frequency by nicotine in neurons pretreated without (-) or with myr-PKC $20-28 .{ }^{*}: p<0.05, t$-test.

\section{Discussion}

Our experiments have shown that, in rat prefrontal cortex, 1) nicotine increased sIPSC in layer $\mathrm{V}$ pyramidal neurons and the firing rate in layer I interneurons, both of which were disrupted by $A \beta ; 2) A \beta$ did not impair nicotinic regulation of sEPSC in layer I interneurons; 3 ) PKC inhibitors differentially interfered with nicotinic regulation of excitatory or inhibitory transmission, mimicking the effect of $A \beta$. These results suggest that $A \beta$ selectively impairs nicotinic regulation of inhibitory inputs to cortical pyramidal neurons, which may involve a PKC-dependent mechanism.

Nicotine often has neuron-specific effects in different networks, which are mediated by different nAChR subtypes $[21,34,35]$. In this study, we have found that nicotine enhances both inhibitory inputs to PFC layer V pyramidal neurons and excitatory inputs to layer I interneurons. In the presence of non- $\alpha 7 \mathrm{nAChR}$ antagonist MEC, both sIPSC and sEPSC are irresponsive to nicotine, suggesting that $\alpha 4 \beta 2$ may mediate these effects of nicotine $[20,36]$. Nicotine does not alter the excitability of layer $\mathrm{V}$ pyramidal neurons, but significantly increases the firing rate of layer I interneurons, an effect mediated by both $\alpha 7$ and non- $\alpha 7$ nAChRs. Involvement of different $n A C h R s$ may also suggest distinct roles of nicotine in regulating neuronal functions. In hippocampal cultures, $\alpha 7$ and $\alpha 4 \beta 2$ displayed distinct patterns of expression, with $\alpha 7$ preferentially present on the somatodendrites whereas $\alpha 4 \beta 2$ distributed on both the axonal and dendritic compartments [37]. Our results are consistent with the finding that presynaptic $\alpha 4 \beta 2$ receptors contribute to neurotransmission $[38,39]$ and both somatodendritic $\alpha 7$ and presynaptic $\alpha 4 \beta 2$ receptors modulate neuronal excitability $[12,40,41]$.

Both $A \beta$ accumulation and nicotinic deficits occur in the progression of $\mathrm{AD}[42,43]$. $\mathrm{A} \beta$ peptide may alter nicotinic function in several ways. Direct binding of $A \beta_{1-42}$ to $\alpha 7$ receptors leads to inhibition of channel open probability [44] and ionic current $[43,45]$. However, several lines of evidence suggest that direct inhibition of $n A C h R s$ by $A \beta$ might not be enough to explain $A \beta$-induced impairment of nicotinic functions. In hippocampal interneurons of transgenic mice overexpressing $A \beta, \alpha 7 \mathrm{nAChRs}$ are still functioning [46]. $A \beta$ is able to elevate presynaptic calcium levels, which could occlude the enhancing effect of nicotine on calcium-dependent transmitter release [47]. Calcium and PKC have been found to be involved in nicotine-facilitated neurotransmission in interneurons 
$[48,49]$. Our results demonstrate that PKC inhibitor has a similar effect on nicotinic regulation of synaptic transmission as $A \beta$, suggesting that PKC could be an important mediator in $\mathrm{A} \beta$-induced impairment of $\mathrm{nAChR}$ functions in $\mathrm{AD}$. It supports the idea that PKC-related intervention might be promising for AD treatment [50-52].

In this study, we have found that nicotinic regulation of interneuron firing and GABAergic inputs to pyramidal neurons are selectively susceptible to $A \beta$, while nicotinic regulation of excitatory inputs to interneurons is relatively preserved. It suggests that interneuronmediated inhibition and its excitability are $A \beta$ targets. It is known that inhibitory terminals of fast-spiking interneurons are better equipped to support prolonged transmitter release at a higher frequency in comparison with pyramidal neurons [53]. Electrical and chemical connections of cortical interneurons promote their synchronous firing, thus interneurons play an important role in coordinating cortical activity [54,55], which is critical for working memory [56]. The A $\beta$-induced selective impairment of nicotinic regulation of inhibitory inputs to cortical principal neurons could contribute to the dysfunction of neuronal network and the imbalance of inhibition/excitation, leading to interruption of working memory.

\section{Methods}

\section{Drugs}

A $\beta$ oligomer was prepared as described previously [28,57]. Nicotine (Sigma), mecamylamine (Sigma), methyllycaconitine (Tocris), GF109203X (Tocris), myr-PKC $20-28$ (Calbiochem) were made freshly from stocks.

\section{Animals}

The transgenic mice that coexpress a total of five FAD mutations [APP K670N/M671L (Swedish) + I716V (Florida) + V717I (London) and PS1 M146L + L286V] [31] was a generous gift from Dr. William E. Van Nostrand (Stony Brook University). Transgenic males (Hets) were bred with mature females (WT). Genotyping were performed by PCR.

\section{Slice preparation}

All experiments were performed under the supervision of State University of New York at Buffalo Animal Care Committee. Sprague Dawley rats (3-5 weeks old) were anesthetized with 2-bromo-2-chloro-1,1,1-trifluoroethane $(1 \mathrm{ml} / 100 \mathrm{~g})$ inhalation before decapitation [28,58]. Brains were quickly removed and sliced $(300 \mu \mathrm{m})$ with a Leica (Nussloch, Germany) VP1000S Vibratome. Slices were then incubated in artificial CSF (in mM: $130 \mathrm{NaCl}, 26$ $\mathrm{NaHCO}_{3}, 3 \mathrm{KCl}, 5 \mathrm{MgCl}_{2}, 1.25 \mathrm{NaH}_{2} \mathrm{PO}_{4}, 2 \mathrm{CaCl}_{2}$, and 10 glucose, $\mathrm{pH} 7.4,300$ mOsm) bubbled with $95 \% \mathrm{O}_{2}$ and $5 \% \mathrm{CO}_{2}$.

\section{Patch clamp recordings}

Voltage clamp recording of synaptic currents in slices was performed as described previously [33,59]. The PFC slice was placed in a perfusion chamber attached to the fixed stage of an upright microscope (Olympus Optical, Melville, NY) and submerged in continuously flowing ACSF. For sIPSC recording, patch electrode (3-5 M 2 ) was filled with the following solution (in $\mathrm{mM}$ ): $100 \mathrm{CsCl}$, 10 HEPES, $1 \mathrm{MgCl}_{2}$, 1 EGTA, $30 \mathrm{~N}$-methyl-d-glucamine (NMG), 5 MgATP, $0.5 \mathrm{Na}_{2} \mathrm{GTP}$ and 12 phosphocreatine, $\mathrm{pH}$ 7.2-7.3, 270-280 mOsm. CNQX or DNQX (20 $\mu \mathrm{M})$ and APV $(40 \mu \mathrm{M})$ were added to ACSF to block AMPA and NMDA receptors. For sEPSC recording, the internal solution was composed of (in $\mathrm{mM}$ ): $130 \mathrm{Cs}$-methanesulfonate, $10 \mathrm{HEPES}, 10 \mathrm{CsCl}, 4 \mathrm{NaCl}, 1 \mathrm{MgCl}_{2}, 1 \mathrm{EGTA}, 5$ NMG, 5 MgATP, and $0.5 \mathrm{Na}_{2}$ GTP and 12 phosphocreatine, $\mathrm{pH} 7.2,275-290 \mathrm{mOsm}$. Bicuculline $(10 \mu \mathrm{M})$ was added to ACSF to block $\mathrm{GABA}_{\mathrm{A}}$ receptors. Cells were visualized with a 40x water-immersion lens and illuminated with near infrared (IR) light, and the image was detected with an IR-sensitive CCD camera. A Multiclamp 700A amplifier (Axon Instruments) was used for the recording. Tight seals (2-10 G $\Omega$ ) from visualized neurons were obtained by applying negative pressure. The membrane was disrupted with additional suction, and the whole-cell configuration was obtained. The access resistances were 13-18 $\mathrm{M} \Omega$. The membrane potential was held at $-70 \mathrm{mV}$.

Mini Analysis program (Synaptosoft, Leonia, NJ) was used to analyze synaptic activity. Individual synaptic events with fast onset and exponential decay kinetics were captured with threshold detectors in Mini Analysis software. All quantitative measurements were taken 4-6 min after drug application. Spontaneous IPSC or EPSC recordings of 3 min under each condition were used for obtaining cumulative distribution plots of the amplitudes and inter-event intervals. To measure cell excitability, the whole-cell current-clamp technique $[33,59]$ was used to record spikes evoked by a $500 \mathrm{~ms}$ depolarizing current pulse. The amplitude of injected current was adjusted so that 5-7 spikes were elicited in the control ACSF solution. The patch electrode was filled with an internal solution containing (in $\mathrm{mM}$ ): $60 \mathrm{~K}_{2} \mathrm{SO}_{4}$, 60 NMG, 40 HEPES, $4 \mathrm{MgCl}_{2}$, 0.5 BAPTA, 12 phosphocreatine, $2 \mathrm{Na}_{2}$ ATP and $0.2 \mathrm{Na}_{3} \mathrm{GTP}, \mathrm{pH}$ 7.2-7.3, 265-270 mOsm. The firing rate of each neuron was averaged from 10 consecutive traces under each condition.

\section{Data analysis}

Statistical comparisons of the synaptic currents were made using the Kolmogorov-Smirnov (K-S) test. Experiments with two groups were analyzed statistically using unpaired Student's $t$-tests. Experiments with more than 
two groups were subjected to one-way ANOVA, followed by post hoc Tukey tests.

Numerical values were expressed as mean \pm SEM.

\section{Competing interests}

The authors declare that they have no competing interests.

\section{Authors' contributions}

GJC and ZX performed experiments and analyzed data. ZY designed experiments and wrote the manuscript. All authors read and approved the final manuscript.

\section{Acknowledgement}

This work was supported by NIH grant (AG21923) to Z.Y. and by NSFC grant (81171197) and Bureau of Health of Chongqing Medical Research Grant (2011-1-018) to G-J. C. We would like to thank Xiaoqing Chen for her technical support.

Received: 18 September 2012 Accepted: 4 January 2013

Published: 17 January 2013

\section{References}

1. Esteban JA: Living with the enemy: a physiological role for the betaamyloid peptide. Trends Neurosci 2004, 27:1-3.

2. Price DL, Sisodia SS: Mutant genes in familial alzheimer's disease and transgenic models. Annu Rev Neurosci 1998, 21:479-505.

3. Selkoe DJ: Alzheimer's disease: genes, proteins, and therapy. Physiol Rev 2001, 81:741-766.

4. Tanzi RE, Bertram L: Twenty years of the alzheimer's disease amyloid hypothesis: a genetic perspective. Cell 2005, 120:545-555.

5. Yankner BA, Duffy LK, Kirschner DA: Neurotrophic and neurotoxic effects of amyloid beta protein: reversal by tachykinin neuropeptides. Science 1990, 250:279-282.

6. Mattson MP: Cellular actions of beta-amyloid precursor protein and its soluble and fibrillogenic derivatives. Physiol Rev 1997, 77:1081-1132.

7. Selkoe DJ: Alzheimer's disease is a synaptic failure. Science 2002, 298:789-791.

8. Palop JJ, Chin J, Mucke L: A network dysfunction perspective on neurodegenerative diseases. Nature 2006, 443:768-773.

9. Bartus RT, Dean RL 3rd, Beer B, Lippa AS: The cholinergic hypothesis of geriatric memory dysfunction. Science 1982, 217:408-414.

10. Paterson D, Nordberg A: Neuronal nicotinic receptors in the human brain. Prog Neurobiol 2000, 61:75-111.

11. Perry E, Martin-Ruiz C, Lee M, Griffiths M, Johnson M, Piggott M, Haroutunian V, Buxbaum JD, Nasland J, Davis K, Gotti C, Clementi F, Tzartos S, Cohen O, Soreq H, Jaros E, Perry R, Ballard C, McKeith I, Court J: Nicotinic receptor subtypes in human brain ageing, Alzheimer and lewy body diseases. Eur J Pharmacol 2000, 393:215-222.

12. Lena C, Changeux JP, Mulle C: Evidence for "preterminal" nicotinic receptors on GABAergic axons in the rat interpeduncular nucleus. J Neurosci 1993, 13:2680-2688.

13. Zarei MM, Radcliffe KA, Chen D, Patrick JW, Dani JA: Distributions of nicotinic acetylcholine receptor alpha7 and beta2 subunits on cultured hippocampal neurons. Neuroscience 1999, 88:755-764.

14. Dani JA, Bertrand D: Nicotinic acetylcholine receptors and nicotinic cholinergic mechanisms of the central nervous system. Annu Rev Pharmacol Toxicol 2007, 47:699-729.

15. Levin ED, McClernon FJ, Rezvani AH: Nicotinic effects on cognitive function: behavioral characterization, pharmacological specification, and anatomic localization. Psychopharmacology (Berl) 2006, 184:523-539.

16. Nott A, Levin ED: Dorsal hippocampal alpha7 and alpha4beta2 nicotinic receptors and memory. Brain Res 2006, 1081:72-78.

17. Grottick AJ, Higgins GA: Effect of subtype selective nicotinic compounds on attention as assessed by the five-choice serial reaction time task. Behav Brain Res 2000, 117:197-208.

18. Mirza NR, Stolerman IP: Nicotine enhances sustained attention in the rat under specific task conditions. Psychopharmacology (Berl) 1998, 138:266-274.

19. Wilkinson DG, Francis PT, Schwam E, Payne-Parrish J: Cholinesterase inhibitors used in the treatment of Alzheimer's disease: the relationship between pharmacological effects and clinical efficacy. Drugs Aging 2004, 21:453-478.

20. Alkondon M, Pereira EF, Eisenberg HM, Albuquerque EX: Nicotinic receptor activation in human cerebral cortical interneurons: a mechanism for inhibition and disinhibition of neuronal networks. J Neurosci 2000 20:66-75.

21. Mansvelder HD, Keath JR, McGehee DS: Synaptic mechanisms underlie nicotine-induced excitability of brain reward areas. Neuron 2002, 33:905-919.

22. Lambe EK, Picciotto MR, Aghajanian GK: Nicotine induces glutamate release from thalamocortical terminals in prefrontal cortex. Neuropsychopharmacology 2003, 28:216-225.

23. Ohnishi M, Katsuki H, Takagi M, Kume T, Akaike A: Long-term treatment with nicotine suppresses neurotoxicity of, and microglial activation by, thrombin in cortico-striatal slice cultures. Eur J Pharmacol 2009, 602:288-293.

24. Chu Z, Galarreta M, Hestrin S: Synaptic interactions of late-spiking neocortical neurons in layer 1. J Neurosci 2003, 23:96-102.

25. Zhu Y, Zhu Jj: Rapid arrival and integration of ascending sensory information in layer 1 nonpyramidal neurons and tuft dendrites of layer 5 pyramidal neurons of the neocortex. J Neurosci 2004, 24:1272-1279.

26. Zhou FM, Hablitz JJ: Layer I neurons of rat neocortex. I. Action potential and repetitive firing properties. J Neurophysiol 1996, 76:651-667.

27. Tu B, Gu Z, Shen JX, Lamb PW, Yakel JL: Characterization of a nicotinesensitive neuronal population in rat entorhinal cortex. J Neurosci 2009, 29:10436-10448.

28. Gu Z, Liu W, Yan Z: $\beta$-amyloid impairs AMPA receptor trafficking and function by reducing CaMKII synaptic distribution. J Biol Chem 2009, 284:10639-10649.

29. Gu Z, Yakel JL: Timing-dependent septal cholinergic induction of dynamic hippocampal synaptic plasticity. Neuron 2011, 71:155-165.

30. Liu W, Dou F, Feng J, Yan Z: RACK1 is involved in $\beta$-amyloid impairment of muscarinic regulation of GABAergic transmission. Neurobiol Aging 2011, 32:1818-1826.

31. Oakley H, Cole SL, Logan S, Maus E, Shao P, Craft J, Guillozet-Bongaarts A, Ohno M, Disterhoft J, Van Eldik L, Berry R, Vassar R: Intraneuronal betaamyloid aggregates, neurodegeneration, and neuron loss in transgenic mice with five familial Alzheimer's disease mutations: potential factors in amyloid plaque formation. J Neurosci 2006, 26:10129-10140.

32. Tyszkiewicz JP, Yan Z: $\beta$-amyloid peptides impair PKC-dependent functions of metabotropic glutamate receptors in prefrontal cortical neurons. J Neurophysiology 2005, 93:3102-3111.

33. Zhong P, Gu Z, Wang X, Jiang H, Feng J, Yan Z: Impaired modulation of GABAergic transmission by muscarinic receptors in a mouse transgenic model of Alzheimer's disease. J Biol Chem 2003, 278:26888-26896.

34. Frazier CJ, Rollins YD, Breese CR, Leonard S, Freedman R, Dunwiddie TV: Acetylcholine activates an alpha-bungarotoxin-sensitive nicotinic current in rat hippocampal interneurons, but not pyramidal cells. J Neurosci 1998, 18:1187-1195

35. Zhang $\mathrm{H}$, Sulzer D: Frequency-dependent modulation of dopamine release by nicotine. Nat Neurosci 2004, 7:581-582.

36. Couey JJ, Meredith RM, Spijker S, Poorthuis RB, Smit AB, Brussaard AB, Mansvelder HD: Distributed network actions by nicotine increase the threshold for spike-timing-dependent plasticity in prefrontal cortex. Neuron 2007, 54:73-87.

37. $\mathrm{Xu}$ J, Zhu Y, Heinemann SF: Identification of sequence motifs that target neuronal nicotinic receptors to dendrites and axons. J Neurosci 2006 26:9780-9793.

38. Sher E, Chen Y, Sharples TJ, Broad LM, Benedetti G, Zwart R, McPhie Gl, Pearson KH, Baldwinson T, De Filippi G: Physiological roles of neuronal nicotinic receptor subtypes: new insights on the nicotinic modulation of neurotransmitter release, synaptic transmission and plasticity. Curr Top Med Chem 2004, 4:283-297.

39. Wonnacott S: Presynaptic nicotinic ACh receptors. Trends Neurosci 1997, 20:92-98.

40. Alkondon M, Pereira EF, Barbosa CT, Albuquerque EX: Neuronal nicotinic acetylcholine receptor activation modulates gamma-aminobutyric acid release from CA1 neurons of rat hippocampal slices. J Pharmacol Exp Ther 1997, 283:1396-1411.

41. Mameli-Engvall M, Evrard A, Pons S, Maskos U, Svensson TH, Changeux JP, Faure P: Hierarchical control of dopamine neuron-firing patterns by nicotinic receptors. Neuron 2006, 50:911-921. 
42. Dineley KT: Beta-amyloid peptide-nicotinic acetylcholine receptor interaction: the two faces of health and disease. Front Biosci 2007 12:5030-5038

43. Oddo S, LaFerla FM: The role of nicotinic acetylcholine receptors in Alzheimer's disease. J Physiol Paris 2006, 99:172-179.

44. Pettit $D L$, Shao Z, Yakel JL: Beta-Amyloid(1-42) peptide directly modulates nicotinic receptors in the rat hippocampal slice. J Neurosci 2001, 21:RC120.

45. Liu Q, Kawai H, Berg DK: Beta -amyloid peptide blocks the response of alpha 7-containing nicotinic receptors on hippocampal neurons. Proc Natl Acad Sci U S A 2001, 98:4734-4739.

46. Spencer JP, Weil A, Hill K, Hussain I, Richardson JC, Cusdin FS, Chen YH, Randall AD: Transgenic mice over-expressing human beta-amyloid have functional nicotinic alpha 7 receptors. Neuroscience 2006, 137:795-805.

47. Dougherty JJ, Wu J, Nichols RA: Beta-amyloid regulation of presynaptic nicotinic receptors in rat hippocampus and neocortex. J Neurosci 2003, 23:6740-6747.

48. Klein RC, Yakel JL: Paired-pulse potentiation of alpha7-containing nAChRs in rat hippocampal CA1 stratum radiatum interneurones. J Physiol 2005, 568:881-889.

49. Wanaverbecq N, Semyanov A, Pavlov I, Walker MC, Kullmann DM: Cholinergic axons modulate GABAergic signaling among hippocampal interneurons via postsynaptic alpha 7 nicotinic receptors. J Neurosci 2007, 27:5683-5693.

50. Alkon DL, Sun MK, Nelson TJ: PKC signaling deficits: a mechanistic hypothesis for the origins of Alzheimer's disease. Trends Pharmacol SCi 2007, 28:51-60.

51. Sun MK, Alkon DL: Bryostatin-1: pharmacology and therapeutic potential as a CNS drug. CNS Drug Rev 2006, 12:1-8.

52. Youdim MB, Weinstock M: Molecular basis of neuroprotective activities of rasagiline and the anti-Alzheimer drug TV3326 [(N-propargyl-(3R) aminoindan-5-YL)-ethyl methyl carbamate]. Cell Mol Neurobiol 2001, 21:555-573.

53. Galarreta M, Hestrin S: Frequency-dependent synaptic depression and the balance of excitation and inhibition in the neocortex. Nat Neurosci 1998 1:587-594.

54. Galarreta M, Hestrin S: A network of fast-spiking cells in the neocortex connected by electrical synapses. Nature 1999, 402:72-75.

55. Whittington MA, Traub RD: Interneuron diversity series: inhibitory interneurons and network oscillations in vitro. Trends Neurosci 2003, 26:676-682

56. Howard MW, Rizzuto DS, Caplan JB, Madsen JR, Lisman J, AschenbrennerScheibe R, Schulze-Bonhage A, Kahana MJ: Gamma oscillations correlate with working memory load in humans. Cereb Cortex 2003, 13:1369-1374.

57. Dahlgren KN, Manelli AM, Stine WB Jr, Baker LK, Krafft GA, LaDu MJ: Oligomeric and fibrillar species of amyloid-beta peptides differentially affect neuronal viability. J Biol Chem 2002, 277:32046-32053.

58. Feng J, Cai $X$, Zhao J, Yan Z: Serotonin receptors modulate GABA(A) receptor channels through activation of anchored protein kinase $C$ in prefrontal cortical neurons. J Neurosci 2001, 21:6502-6511.

59. Chen G, Kittler JT, Moss SJ, Yan Z: Dopamine D3 receptors regulate GABAA receptor function through a phospho-dependent endocytosis mechanism in nucleus accumbens. J Neurosci 2006, 26:2513-2521.

\section{doi:10.1186/1750-1326-8-3}

Cite this article as: Chen et al:: $A \beta$ impairs nicotinic regulation of inhibitory synaptic transmission and interneuron excitability in prefrontal cortex. Molecular Neurodegeneration 2013 8:3.

\section{Submit your next manuscript to BioMed Central and take full advantage of:}

- Convenient online submission

- Thorough peer review

- No space constraints or color figure charges

- Immediate publication on acceptance

- Inclusion in PubMed, CAS, Scopus and Google Scholar

- Research which is freely available for redistribution

Submit your manuscript at www.biomedcentral.com/submit
( Biomed Central 